Laser Chem., 1999, Vol. 19, pp. 325-327

Reprints available directly from the publisher Photocopying permitted by license only
(C) 1999 OPA (Overseas Publishers Association) N.V. Published by license under the Harwood Academic Publishers imprint, part of The Gordon and Breach Publishing Group.

\title{
TIME-RESOLVED RESONANCE RAMAN STUDY OF BIPHENYL OCCLUDED IN THE SUPERCAGES OF FAUJASITIC ZEOLITES
}

\author{
G. BUNTINX* , G. GINESTET, I. GENER, \\ G. COUSTILLIER and C. BRÉMARD \\ Laboratoire de Spectrochimie Infrarouge et Raman UPR-CNRS 2631, \\ Centre $d^{\prime}$ Etudes et de Recherches Lasers et applications, Université de Lille I, \\ Bât. C5, 59655 Villeneuve d' Ascq Cedex, France
}

(Received 21 April 1997)

\begin{abstract}
The laser photolysis $(248 \mathrm{~nm}, 20 \mathrm{~ns})$ of biphenyl (BP, $\left.\mathrm{S}_{0}\right)$ occluded in the void space of faujasitic zeolites $\left(\mathrm{Na}_{n} \mathrm{FAU}\right), \mathrm{Na}_{n}\left(\mathrm{SiO}_{2}\right)_{192-n}\left(\mathrm{AlO}_{2}\right)_{n}$ with $n=0,56,85$ has been studied by time-resolved resonance Raman spectroscopy combined with time-resolved diffuse reflectance UV-visible absorption spectroscopy in the ns $-\mu$ s time scale. The excitation ( $370 \mathrm{~nm}, 8 \mathrm{~ns}$ ) of the RR scattering in the wavelength region of the UV electronic absorption of the transient species provides clear evidence of the radical cation $\left(\mathrm{BP}^{+}\right)$as major species for zeolites $\mathrm{Na}_{n} \mathrm{FAU}(n=56,85)$. The amount of triplet state $\left(\mathrm{BP}, \mathrm{T}_{1}\right)$ depends on the aluminum content and in a less extent on the fluence of the pump laser at the sample.
\end{abstract}

Keywords: Biphenyl; zeolite; time-resolved Raman spectroscopy; diffuse reflectance UVvisible transient absorption; nanosecond

The ever-increasing interest in photophysics and photochemistry in organized and constrained media has recently encouraged the use of the time-resolved resonance Raman spectroscopy to characterize short-lived species generated in the void space of crystalline porous aluminosilicate solids such as faujasitic zeolites $\left(\mathrm{Na}_{n} \mathrm{FAU}\right), \mathrm{Na}_{n^{-}}$ $\left(\mathrm{SiO}_{2}\right)_{192-n}\left(\mathrm{AlO}_{2}\right)_{n}(n=0-96)$. The biphenyl (BP) can gain free access to the $13 \AA$ diameter supercage through the $8 \AA$ diameter 12-ring entrance port of the zeolites. The structure of Biphenyl (BP) is known

\footnotetext{
* Corresponding author.
} 
to change with its physical state. It exists as a planar $\left(D_{2 h}\right)$ structure in the crystalline state above $40 \mathrm{~K}$, but takes twisted $\left(D_{2}\right)$ structure in the gaseous state. The ground electronic state $\left(\mathrm{S}_{0}\right)$, the lowest excited singlet state $\left(\mathrm{S}_{1}\right)$, the lowest excited triplet state $\left(\mathrm{T}_{1}\right)$ as well as the cation radical $\mathrm{BP}^{+}$. and the anion radical $\mathrm{BP}^{-}$. have been well characterized previously in solution [1, 2]. We report here the photophysics of BP occluded in dehydrated faujasitic zeolites $\mathrm{Na}_{n} \mathrm{FAU}(n=0,56,85)$ using time-resolved resonance Raman spectroscopy and time-resolved UV-visible diffuse reflectance spectroscopy in the nano/microsecond time scale.

The freshly dehydrated $\mathrm{Na}_{n} \mathrm{FAU}$ are loaded by the BP molecules through adsorption from the gas phase at different coverages namely $1,2,4,8$ and 16 BP per unit cell (8 supercages). The ( $\left.\mathrm{S}_{0}\right)$ siting location and conformation of BP sorbed in $\mathrm{Na}_{n} \mathrm{FAU}$ at different loading were deduced from FT-Raman spectroscopy as well as molecular dynamics (MD) and Monte Carlo (MC) simulations. These supercages are large enough to accomodate up two BP molecules. BP takes twisted structures in the void space and the average occupation time in one supercage is found to be less than $25 \mathrm{ps}$ from MD data at low coverage. At higher coverage the main trends are retained until the saturation of the void space.

The laser pump excitation $(248 \mathrm{~nm}, 20 \mathrm{~ns}, 0.05-3 \mathrm{~mJ}, 10 \mathrm{~Hz})$ is in resonance with the $S_{n} \leftarrow \mathrm{S}_{0}$ BP transition which occurs around $250 \mathrm{~nm}$ for BP occluded into $\mathrm{Na}_{n} \mathrm{FAU}(n=0,56,85)$. The transient electronic absorption spectra are found to be characteristic of $\mathrm{BP}\left(\mathrm{T}_{1}\right), \mathrm{BP}^{+}$, $\mathrm{BP}^{--}$and to the trapped electrons within the zeolites for all the delays between 1 and $100 \mu$ s [3]. The trapped electrons can be ascribed to $\mathrm{Na}_{4}^{3+}$ as a counter part to $\mathrm{BP}^{+}$.

The probe excitation $(370 \mathrm{~nm}, 8 \mathrm{~ns})$ of the RR scattering in the wavelength region of the UV electronic absorption of the transient species provides clear evidence of the radical cation $\left(\mathrm{BP}^{+}\right)$as major species for zeolites $\mathrm{Na}_{n} \mathrm{FAU}(n=56,85)$ at different delays after the pump pulse for all the experimental coverages. This photoionization is considered to take place by a biphotonic process. The amount of triplet state $\left(\mathrm{BP}, \mathrm{T}_{1}\right)$ depends on the aluminum content of the host and in a less extent on the fluence of the pump laser at the sample. The time-resolved resonance Raman spectra of $\mathrm{BP}$ occluded in $\mathrm{Na}_{56} \mathrm{FAU}$ (Fig. 1) have a good resemblance with that reported previously in 


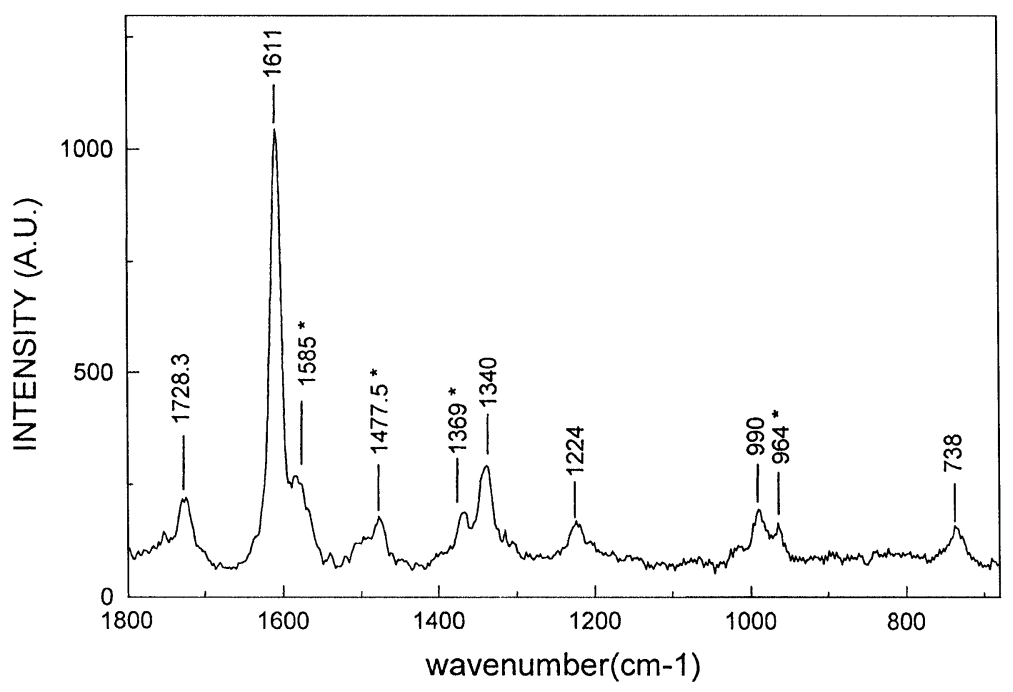

FIGURE 1 Transient Resonance Raman spectrum of BP occluded in $\mathrm{Na}_{56} \mathrm{FAU}$ zeolite excited at $370 \mathrm{~nm}$ and recorded $150 \mathrm{~ns}$ after the pump excitation at $248 \mathrm{~nm}$. The asterisks indicate the $\mathrm{T}_{1}$ bands, the remaining bands are characteristic of the radical cation $\mathrm{BP}^{+}$.

acetonitrile solution [2]. It was recently found that both cation $\mathrm{BP}^{+}$. and anion $\mathrm{BP}^{-}$. radical are generated simultaneously when $\mathrm{BP}$ occluded in $\mathrm{Na}_{56} \mathrm{FAU}$ at high coverage is photoexcited at $266 \mathrm{~nm}$ [3]. Unfortunately, the present time-resolved resonance Raman spectra $(370 \mathrm{~nm})$ do not provide clear evidence of the anion radical.

\section{References}

[1] Sasaki, Y. and Hamaguchi, H. (1994). Spectrochimica. Acta, 50A, 1475.

[2] Buntinx, G. and Poizat, O. (1989). J. Chem. Phys., 91, 2153.

[3] Hashimoto, S., Mutoh, T., Fukumura, H. and Masuhara, H. (1996). J. Chem. Soc., Faraday, 92, 3660. 